\title{
Influence of coronavirus disease 2019 pandemic state of emergency in orthopaedic fracture surgical treatment
}

\author{
Milan M. Mitkovic ${ }^{1,2}$ - Marko Bumbasirevic ${ }^{3,4} \cdot$ Sasa Milenkovic $^{1,2} \cdot$ Djordje Gajdobranski $^{5} \cdot$ Vojislav Bumbasirevic $^{6}$. \\ Milorad B. Mitkovic ${ }^{1}$
}

Received: 7 July 2020 / Accepted: 23 July 2020 / Published online: 29 July 2020

(C) SICOT aisbl 2020

\begin{abstract}
Purpose After the appearance of first COVID-19 cases in Serbia, state of emergency was declared on 15 March 2020 and lasted for 54 days. The aim of this report is to compare orthopaedic fracture frequencies in this period, when the walk was limited at the home mostly, with those during the same part in the previous year with regular state, thus to examine staying at home as a factor influencing the frequency of different fracture types.

Methods There were 86 patients during the state of emergency in year 2020 and 106 patients during the same part of year 2019 with a regular state, having orthopaedic trauma surgery. Number of fractures, gender distribution, and age of patients have been compared between these periods.

Results Total number of fractures decreased for about $19 \%$ during the state of emergency. There was nonsignificant difference in fracture frequency for all skeletal areas $(p>0.05)$, except for distal femoral fractures which occurred more often during the state of emergency $(p<0.05)$. Female ratio was higher during state of emergency than in regular state for femoral neck fractures.

Conclusion Restricted going outside the home for 54 days has the influence in total number of fractures and gender distribution in femoral neck fractures. The method of external fixation used could be assumed as a reducing factor of intraoperative virus pandemic propagation among medical staff.
\end{abstract}

Keywords COVID-19 - Orthopaedic trauma $\cdot$ State of emergency $\cdot$ External fixation

\section{Introduction}

During December 2019, a mysterious outbreak of atypical pneumonia was noticed in Wuhan, capital of Hubei province, China [1]. The first patient with its clinical presence was hospitalized on 12 December 2019 [2]. A cluster of

Milan M. Mitkovic

milanmitkovic@hotmail.com

1 Clinic for Orthopaedics and Traumatology, Clinical Center Nis, Nis, Serbia

2 Faculty of Medicine, University of Nis, Nis, Serbia

3 Clinic for Orthopaedics and Traumatology, Clinical Center of Serbia, Belgrade, Serbia

4 Faculty of Medicine, University of Belgrade, Belgrade, Serbia

5 Institute for Health Care of Children and Youth of Vojvodina, Novi Sad, Serbia

6 Clinical Center of Serbia, Belgrade, Serbia patients with pneumonia of unknown aetiology was reported on 30 December 2019, and the Wuhan Municipal Health Commission had informed World Health Organization (WHO) in that way on 31 December 2019 $[3,4]$. On 7 January 2020, the causative agent of this disease was identified by Chinese Centre for Disease Control and Prevention as a novel coronavirus, and on 12 January 2020, they termed it as severe acute respiratory syndrome coronavirus 2 (SARS-CoV-2). The WHO initially named this virus as $2019-\mathrm{nCoV}$ and this disease was officially and internationally named as COVID-19 (coronavirus disease 2019) on 11 February 2020 [5-7]. The first three cases of the new disease in Europe were reported on 24 January 2020 in France, and the COVID19 surveillance was implemented on 27 January in the WHO European Region [5]. The WHO declared Public Health Emergency of International Concern on 30 January 2020 [6].

The first case of COVID-19 in Serbia was reported on 5 March 2020 and confirmed the day after [8]. The WHO 
declared the outbreak of global pandemic on 11 March 2020, and the Government of Serbia declared the state of emergency from 15 March 2020 until 6 May 2020 [9]. This state included bans on being outside the home (except for emergency health reasons and for some authorized services). This measure had been applied to people of all ages, but it was larger for people older than 65 years. The specificity of these measures gives an opportunity to analyze the orthopaedic healthcare when the people's walk is much limited at the home only than usually, by comparing with the same parts other years when described restrictions are not declared. The aim of this study was to make the above type of comparison regarding orthopaedic trauma surgical treatment. Some details of Serbian hospital services during the pandemic are presented in this paper too.

Liang et al. described three main principles for any operation during COVID-19 pandemic - clinical urgency, patient and health-care worker protection, and conservation of health-care resources [10]. Orthopaedic surgeons have a high responsibility both for them and for the staff and patients as they are leaders in a surgical team. Shortening of the operation time and avoidance of reaming are considered preventive factors in the orthopaedic surgery due to COVID-19 pandemic [11].

\section{Materials and methods}

Distributions of different orthopaedic fracture types occurred during the social ban period (state of emergency due to the COVID-19 pandemic) in year 2020 and during the same part of previous year 2019 (regular state, without social bans), surgically treated at Clinical Center of Nis (Nis, Serbia), were analyzed in this study. The state of emergency in Serbia started on 15 March 2020 and lasted for next 54 days. Social isolation policy during that period included the ban to be outside the home. On workdays, population younger than 65 years had not to be outside the home from six PM till five AM next day. Furthermore, this population had not been allowed to be outside from Saturday two PM till Monday five AM. Throughout the week, population aged 65 years and older have been allowed to go outside just on Sunday between four AM and seven AM. Comparison of fracture distribution between the above mentioned period of social bans in year 2020 and the same part of another year without these bans, could be useful to check if the significant restriction of people to be outside is presented as a factor influencing some fracture type frequency. Number of fractures, gender distribution, and age of patients have been analyzed in this study. There were 192 patients - 83 (43\%) male and 109 (57\%) female patients.

As in many other hospitals, the orthopaedic service at Clinical Center Nis did not include elective patients during the local COVID-19 state of emergency [12-15]. One side of the Clinical Center Nis's building was transformed into
COVID Center (Fig. 1), including the place of Clinic for Orthopaedics and Traumatology. Orthopaedic trauma patients were admitted to the Emergency Center, which was in other side of the building, and the surgery, if it was needed, had been performed in the operating room of the Emergency Center. If the operation was planned to be performed a day later, such patients were transferred to a Military Hospital and then temporarily returned for surgery in Emergency Center. After the operation, patients were transported to the orthopedic trauma ward of the Military Hospital. The number of doctors per shift was decreased and patients were discharged from the hospital as soon as possible after the operation. Several young orthopedic surgeons, as a part of multidisciplinary team, had worked in COVID Center, where there were infected patients with orthopaedic trauma too.

All noted fractures were primarily classified into nine groups, regarding anatomical area: clavicula, humerus, forearm, hand, pelvis, femur, lower leg, and foot. The number of patients in an analyzed year was higher than ten, in femoral and lower leg fracture areas only. Because of that, just these areas were presented by its sub-areas (Table 1). Femoral fractures were divided into proximal femoral fractures (hip fractures), femoral shaft fractures, and distal femoral fractures. Hip fractures were divided into femoral neck, and trochanteric and subtrochanteric fractures. Lower leg fractures were divided into proximal tibial, tibial shaft, distal tibial, and malleolar fractures.

Comparing of distributions was performed by Chi-square test and Fisher's exact test, while ages were compared by Mann-Whitney $U$ test, using IBM SPSS Statistics 22 software, for 0.05 level of significance.

\section{Results}

The number of surgically treated patients with fractures, during the state of emergency in year 2020, was $18.9 \%$ lower in comparison to the same period of year 2019 with regular state. Most of these patients sustained a hip fracture. Average age in patients with a hip fracture was 65 years and older, in both year 2019 and year 2020 (Table 1). The mean age was little lower than 65 years in the state of emergency period in year 2020 while it was little higher in the same part of year 2019 with regular state, but the difference in age between these two period was not significant $(p=0.408)$.

Femoral neck fractures, trochanteric fractures, and lower leg fractures were the only groups with higher number of patients (>10); thus, comparing of gender distributions for a fractured group between the state of emergency period in year 2020 and the same period of year 2019 with regular state was performed there only. This comparison was followed by significant difference in femoral neck group $(p=0.030)$, but not in trochanteric group $(p=0.795)$ and lower leg group $(p=0.458)$. 
Fig. 1 Young physicians from different clinics with appropriate equipment while working at the COVID Center in Clinical Center Nis (a). Face shields were necessary to have it due to the uncovered skin around the shield glasses (b). Data about patients, written primarily by hand, was photographed throw the window pane between the infectious zone and the safe zone (c)
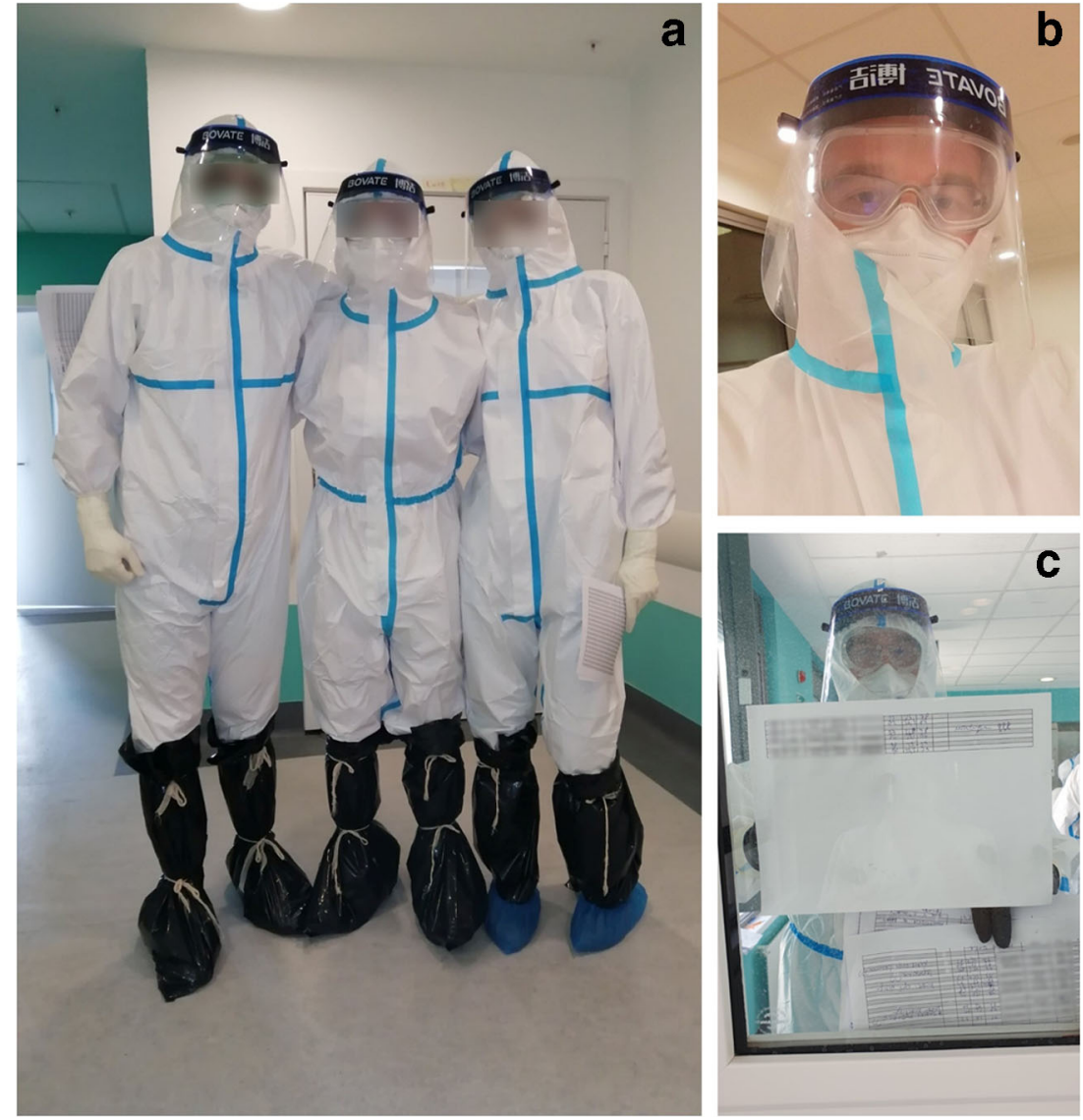

There was nonsignificant difference in femoral neck/ trochanteric fracture relations between the state of emergency period in year 2020 and the same part of year 2019 with regular state $(p=0.295)$.

Comparison of analyzed fracture type distribution in the periods of years 2019 and 2020 had confirmed the significant difference just for distal femoral fractures in relation to both all fractures and to femoral fractures only, with higher values for the period in year 2020 (Table 2).

\section{Discussion}

During the state of emergency due to the COVID-19 pandemic in year 2020 in Serbia, the entire population was limited in being allowed outside. It mostly related to the population aged 65 years and older, who had obligation to stay at home nearly all the time, while population younger than 65 years was allowed to move outside with more freedom during a week. Most patients with a hip fracture were people older than 65 years (who were mostly influenced by staying at home policy). Merilainen et al. found that inability to walk alone outdoors was proved to be a risk factor for femoral neck hip fracture only, while falling indoors was a specific risk factor for trochanteric hip fracture only [16]. Considering that statement, as well as the fact that number of patients with a trochanteric fracture was lower in year 2019 and higher in year 2020 in relation to femoral neck fractures, it could be assumed that falling indoors was proven as a risk factor for trochanteric fractures in our study too. However, it was not statistically proven in our study $(p>0.05)$, but the evidence should not be excluded in another study with a higher number of patients.

The proportion of every analyzed fractured area, in relation to all fractures, was not different between these periods, except for distal femoral fractures. All analyzed fracture areas, except distal femoral fractures, had not different proportions in relation to a wider belonging group (femoral fractures, hip fractures, tibial fractures) between analyzed periods too $(p<0.05)$. Thus, the proportions of distal femoral fractures in relation to both all fractures and femoral fractures only were different between compared periods in years 2019 and 2020 $(p<0.05)$. Based on these data, and on about 19\% lower number of operated fractures during the emergency state in year 2020 in relation to a regular state in year 2019, it can be assumed that the frequency of distal femoral fractures is expected to be higher, while other leg fractures are expected to have lower frequency, during a longer stay at home than usually.

Younger patients generally sustain distal femoral fractures during the high-energy fracture mechanisms, such as traffic 
Table 1 Number of patients (n), gender distribution (male/female, in percentages), and age parameters for different fractured areas during the state of emergency period in year 2020 and the same part of year 2019 with regular state

\begin{tabular}{|c|c|c|c|c|}
\hline & \multicolumn{2}{|l|}{ Year 2019} & \multicolumn{2}{|l|}{ Year 2020} \\
\hline & $\mathrm{n}: \mathrm{M} / \mathrm{F}(\%)$ & $\begin{array}{l}\text { Age (year) } \\
\text { mean (SD) }\end{array}$ & $\mathrm{n}: \mathrm{M} / \mathrm{F}(\%)$ & $\begin{array}{l}\text { Age (year) } \\
\text { mean (SD) }\end{array}$ \\
\hline Clavicula & l & l & 1: $100 / 0$ & 22 \\
\hline Humerus & 7: $57 / 43$ & $57.0(17.4)$ & $3: 33 / 67$ & $44.0(7.5)$ \\
\hline Forearm & $8: 38 / 62$ & $53.0(15.5)$ & 6: $50 / 50$ & 48.3 (11.6) \\
\hline Hand & 1: $100 / 0$ & 41 & 3: $100 / 0$ & $52.3(30.0)$ \\
\hline Pelvis & $2: 100 / 0$ & $69.5(4.9)$ & 1: $100 / 0$ & 88 \\
\hline Femoral neck & 28: $21 / 79$ & $74.1(12.3)$ & $17: 53 / 47$ & $70.0(14.0)$ \\
\hline Trochanteric & $22: 27 / 73$ & 76.7 (7.6) & $21: 24 / 76$ & $72.7(12.3)$ \\
\hline Subtrochanteric & $7: 71 / 29$ & $71.7(17.6)$ & $7: 57 / 43$ & 77.7 (10.2) \\
\hline Femoral shaft & 4: $75 / 25$ & $60.5(17.6)$ & $3: 33 / 67$ & $55.0(34.2)$ \\
\hline Distal femur & $2: 50 / 50$ & $66.5(16.3)$ & $8: 38 / 62$ & $64.0(18.8)$ \\
\hline Patella & $3: 33 / 67$ & $55.0(16.5)$ & $2: 0 / 100$ & $59.0(1.4)$ \\
\hline Proximal tibia & 1: $100 / 0$ & 52 & 2: $0 / 100$ & $60.5(0.7)$ \\
\hline Tibial shaft & 11: $73 / 27$ & $48.9(9.4)$ & $6: 83 / 17$ & 48.5 (12.6) \\
\hline Distal tibia & I & I & $2: 50 / 50$ & $47.0(35.3)$ \\
\hline Malleolar & 10: $40 / 60$ & $61.2(9.8)$ & 3: $0 / 100$ & $64.7(4.0)$ \\
\hline Foot & l & l & 1: 44/56 & 41 \\
\hline Total & 106: 42/58 & $66.1(15.6)$ & $86: 44 / 56$ & $63.7(18.1)$ \\
\hline
\end{tabular}

accidents, while elderly patients sustain these fractures mostly as a low-energy trauma, such as in ground-level falls $[17,18]$. There were both younger and older than 65 years patients who sustained a distal femoral fracture in this study, in analyzed periods of both years. Thus, even the people were at home significantly for more longer time during the state of emergency in year 2020 than in the same period of the previous year with regular state, the increase in the number of distal femoral fractures for the period of year 2020 could be related to not only low-energy mechanisms but also high-energy mechanisms.

Hip fractures and malleolar fractures are mostly caused by low-energy mechanism, while tibial shaft and distal tibial fractures are mostly present by high-energy mechanism [19-24]. In this study, there was no difference between the state of emergency in year 2020 and regular state in the same period of year 2019 regarding hip, tibial shaft, distal tibial, and malleolar fracture proportions to wider belonging groups of fractures $(p>0.05)$. These data, including the decrease in absolute number of patients for all above mentioned fractures during the state of emergency, support the assumption that longer stay at home does not influence fracture type frequency on the basis of the energy of trauma only, but on other bases too.

Orthopaedic surgeons are at risk during the COVID-19 pandemic as a place of work could be contaminated [25]. Intramedullary reaming is considered a factor generating aerosol particles [26]. The 2019-nCoV virus could be propagated by the aerosol because a virus survives within particles of $<$ $0.5 \mu \mathrm{m}$ suspended in the air [27]. Fat embolism and respiratory complications, as potential consequences of intramedullary reaming, are additional factors contributing to avoid reaming in patients with confirmed or suspected COVID-19 infection [11, 28, 29]. Most of the fractures in our study were femoral fractures, both in year 2020 and in year 2019. Due to the above mentioned reaming risks, internal fixation of femoral fractures during COVID-19 pandemic
Table 2 Comparison of a fracture distribution in an area (rows) inside a wider fracture group (columns) between the state of emergency period in year 2020 and the same part of year 2019 with regular state

\begin{tabular}{lllll}
\hline & All fractures $(p)$ & Femoral fractures $(p)$ & Hip fractures $(p)$ & Lower leg fractures $(p)$ \\
\hline Clavicula & 0.448 & & & \\
Humerus & 0.516 & & & \\
Forearm & 0.880 & & & \\
Hand & 0.327 & & & \\
Pelvis & 0.578 & & 0.252 & \\
Femoral neck & 0.280 & 0.114 & 0.412 & \\
Trochanteric & 0.545 & 0.770 & 0.517 & \\
Subtrochanteric & 0.684 & 0.814 & & \\
Femoral shaft & 0.614 & 0.566 & & \\
Distal femur & 0.045 & 0.045 & & 0.541 \\
Patella & 0.598 & & & 0.131 \\
Proximal tibia & 0.588 & & & 0.282 \\
Tibial shaft & 0.409 & & & \\
Distal tibia & 0.199 & & & \\
Malleolar & 0.103 & 0.488 & & \\
Foot &
\end{tabular}




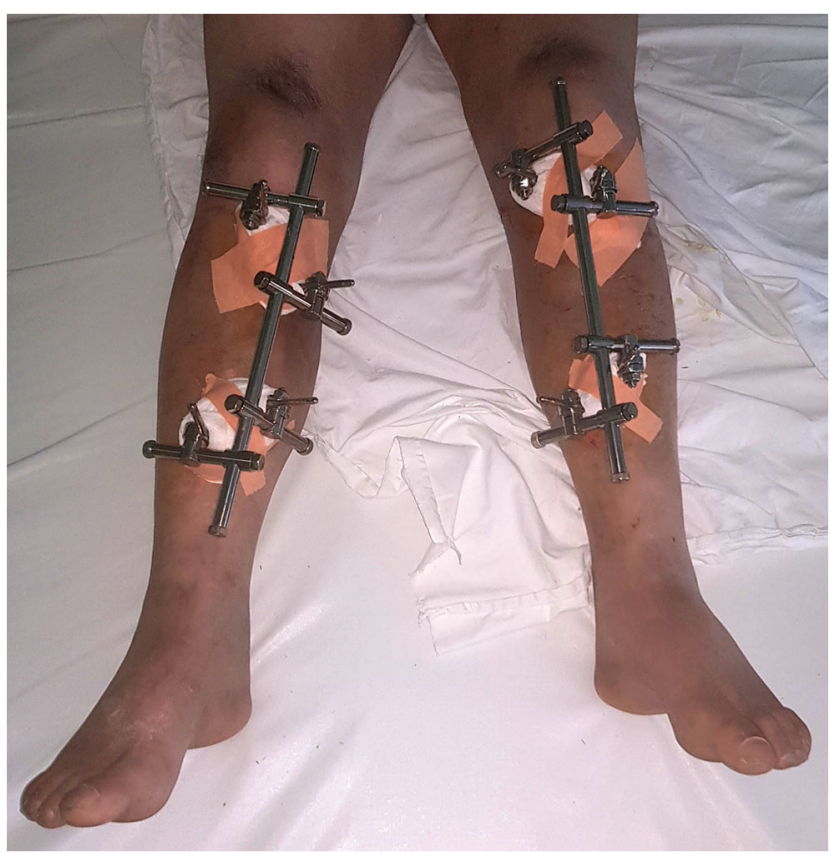

Fig. 2 Mitkovic type external fixator with high adaptable unilateral frame used in definitive treatment of bilateral tibial shaft fractures after a closed reduction

could be more advised to be performed using extramedullary instead intramedullary internal fixation. Self-dynamisable internal fixator, as an extramedullary method, was often used in Clinical Center Nis [30].

In our centres, tibial shaft fractures were treated by $3 \mathrm{D}$ unilateral Mitkovic type external fixator having a high adaptable frame (Fig. 2). The method and device provide a possibility of short time for the fixator application (about 8-15 min without the need for guidance in pin application), closed fracture reduction, and possibilities of postoperative additional fracture reduction if needed [31]. Postoperative hospitalization time for closed fractures is short (usually 1-2 days). Using of a cylindrical protector for soft tissues while drilling could be considered an additional preventive pandemic measure in an operating room.

According to our study, it could be concluded that the total number of orthopaedic fractures for surgical treatment was lesser for the period of 54 days with measures during the COVID-19 social bans in relation to the same period in a year without the bans. Proportions of different fractured areas were not significantly influenced by the state of emergency, except for distal femoral fractures which had been occurred more often during this state. Gender distribution in patients with femoral neck fractures was more equable during the state of emergency than in regular state. The method of closed external fixation of tibia can be confirmed as a good alternative to reduce operation time, intraoperative aerosolization of the virus, and hospitalization time, contributing to the prevention of medical staff infection.
Funding information This work is a part of the project "Virtual human osteoarticular system and its application in preclinical and clinical practice" (No. III41017) funded by the Ministry of Education, Science and Technological Development of Republic of Serbia.

\section{Compliance with ethical standards}

Conflict of interest The author Milorad B Mitkovic at this moment has license agreement with producer Ortokon Ltd. Other authors declare no conflict of interest.

\section{References}

1. Jasper FC, Kin-Hang K, Zheng Z, Hin C, Kelvin KT, Shuofeng Y, Kwok-Yung Y (2020) Genomic characterization of the 2019 novel human-pathogenic coronavirus isolated from a patient with atypical pneumonia after visiting Wuhan. Emerg Microbes Infect 9(1):221236. https://doi.org/10.1080/22221751.2020.1719902

2. Wu F, Zhao B, Chen YM, Wang W, Song ZG, Hu Y, Tao ZW, Tian JH, Pei YY, Yuan ML, Zhang YL, Dai FH, Liu Y, Wang QM, Zheng JJ, Xu L, Holmes EC, Zhang YZ (2020) A new coronavirus associated with human respiratory disease in China. Nature 579: 265-269. https://doi.org/10.1038/s41586-020-2008-3

3. Liu N, Zhang F, Wei C, Jia Y, Shang Z, Sun L, Wu L, Sun Z, Zhou Y, Wang Y, Liu W (2020) Prevalence and predictors of PTSS during COVID-19 outbreak in China hardest-hit areas: gender differences matter. Psychiatry Res 287:112921. https://doi.org/10. 1016/j.psychres.2020.112921

4. Chauhan V, Galwankar S, Arquilla B, Garg M, Di Somma S, ElMenyar A, Krishnan V, Gerber J, Holland R, Stawicki SP (2020) Novel coronavirus (COVID-19): leveraging telemedicine to optimize care while minimizing exposures and viral transmission. J Emerg Trauma Shock 13(1):20-24. https://doi.org/10.4103/JETS. JETS_32_20

5. Spiteri G, Fielding J, Diercke M, Campese C, Enouf V, Gaymard A, Bella A, Sognamiglio P, Sierra Moros MJ, Riutort AN, Demina YV, Mahieu R, Broas M, Bengner M, Buda S, Schilling J, Filleul L, Lepoutre A, Saura C, Mailles A, Levy-Bruhl D, Cignard B, Bernard-Stoecklin S, Behillil S, van der Werf S, Valette M, Lina B, Riccardo F, Nicastri E, Casas I, Larrauri A, Castell MS, Pozo F, Maksyutov RA, Martin C, Ranst MV, Bossuyt N, Siira L, Sane J, Tegmark-Wisell K, Palmerus M, Broberg EK, Beaute J, Jorgensen P, Bundle N, Pereyaslov D, Adlhoch C, Pukkila J, Pebody R, Olsen S, Ciancio BC (2020) First cases of coronavirus disease 2019 (COVID-19) in the WHO European Region, 24 January to 21 February 2020. Euro Surveill 25(9):2000178. https://doi.org/10. 2807/1560-7917.ES.2020.25.9.2000178

6. Sohrabi C, Alsafi Z, O’Neil N, Khan M, Kerwan A, Al-Jabir A, Iosifidis C, Agha R (2020) World Health Organization declares global emergency: a review of the 2019 novel coronavirus (COVID-19). Int J Surg 76:71-76. https://doi.org/10.1016/j.ijsu. 2020.02.034

7. Meng Y, Leng K, Shan L, Guo M, Zhou J, Tian Q, Hai Y (2020) A clinical pathway for pre-operative screening of COVID-19 and its influence on clinical outcome in patients with traumatic fractures. Int Orthop. https://doi.org/10.1007/s00264-020-04645-3

8. Stasevic-Karlicic I, Djordjevic V, Stasevic M, Subotic T, Filipovic Z, Ignjatovic-Ristic D, Janjic V (2020) Perspectives on mental health services during the COVID-19 epidemic in Serbia. Srp Arh Celok Lek. https://doi.org/10.2298/SARH200504028S

9. Amirhossein T, Azam R, Sara KA (2020) COVID-19 battle during the toughest sanctions against Iran. Lancet 395(10229): 1035-1036. https://doi.org/10.1016/s0140-6736(20)30668-1 
10. Liang ZC, Wang W, Murphy D, Po Hui JH (2020) Novel coronavirus and orthopaedic surgery: early experiences from Singapore. J Bone Joint Surg Am 102(9):745-749. https://doi.org/10.2106/jbjs. 20.00236

11. Liang ZC, Chong MSY, Sim MA, Lim JL, Castaneda P, Green DW, Fisher D, Ti LK, Murphy D, Hui JHP (2020) Surgical considerations in patients with COVID-19: what orthopaedic surgeons should know. J Bone Joint Surg Am 102(11):e50 (1-8). https://doi. org/10.2106/jbjs.20.00513

12. Luengo-Alonso G, Perez-Tabernero FG, Tovar-Bazaga M, Arguello-Cuenca JM, Calvo E (2020) Critical adjustments in a department of orthopaedics through the COVID-19 pandemic. Int Orthop. https://doi.org/10.1007/s00264-020-04647-1

13. Grassi A, Pizza N, Tedesco D, Zaffagnini (2020) The COVID-19 outbreak in Italy: perspectives from an orthopaedic hospital. Int Orthop. https://doi.org/10.1007/s00264-020-04617-7

14. Randelli PS, Compagnoni R (2020) Management of orthopaedic and traumatology patients during the coronavirus disease (COVID-19) pandemic in northern Italy. Knee Surg Sports Traumatol Arthrosc 28(6):1683-1689. https://doi.org/10.1007/ s00167-020-06023-3

15. Zagra L, Faraldi M, Pregliasco F, Vinci A, Lombardi G, Ottaiano I, Accetta R, Perazzo P, D’Apolito R (2020) Changes of clinical activities in an orthopaedic institute in North Italy during the spread of COVID-19 pandemic: a seven-week observational analysis. Int Orthop. https://doi.org/10.1007/s00264-020-04590-1

16. Merilainen S, Nevalainen T, Luukinen H, Jalovaara P (2002) Risk factors for cervical and trochanteric hip fracture during a fall on the tip. Scand J Prim Health Care 20(3):188-192. https://doi.org/10. 1080/028134302760234672

17. Martinet O, Cordey J, Harder Y, Maier A, Bühler M, Barraud GE (2000) The epidemiology of fractures of the distal femur. Injury 31(3):62-63. https://doi.org/10.1016/s0020-1383(00)80034-0

18. Elsoe R, Ceccotti AA, Larsen P (2018) Population-based epidemiology and incidence of distal femur fractures. Int Orthop 42(1):191196. https://doi.org/10.1007/s00264-017-3665-1

19. Sheehan SE, Shyu JY, Weaver MJ, Sodickson AD, Khurana B (2015) Proximal femoral fractures: what the orthopaedic surgeon wants to know. Radiographics 35(5):1563-1584. https://doi.org/10. 1148/rg.2015140301

20. Larsen P, Elsoe R, Hansen SH, Graven-Nielsen T, Laessoe U, Rasmussen S (2015) Incidence and epidemiology of tibial shaft fractures. Injury 46(4):746-750. https://doi.org/10.1016/j.injury. 2014.12.027

21. Christiansen BA, Harrison SL, Fink HA, Lane NE (2018) Incident fracture is associated with a period of accelerated loss of hip BMD: the study of osteoporotic fractures. Osteoporos Int 29(10):22012209. https://doi.org/10.1007/s00198-018-4606-6

22. Boszczyk A, Fudalej M, Kwapisz S, Klimek U, Maksymowicz M, Kordasiewicz B, Rammelt S (2018) Ankle fracture - correlation of Lauge-Hansen classification and patient reported fracture mechanism. Forensic Sci Int 282:94-100. https://doi.org/10.1016/j. forsciint.2017.11.023

23. Barile A, Bruno F, Arrigoni F, Splendiani A, Di Cesare E, Zappia M, Guglielmi G, Masciocchi C (2017) Emergency and trauma of the ankle. Semin Musculoskelet Radiol 21(3):282-289. https://doi. org $/ 10.1055 / \mathrm{s}-0037-1602408$

24. Zelle BA, Dang KH, Ornell SS (2019) High-energy tibial pilon fractures: an instructional review. Int Orthop 43(8):1939-1950. https://doi.org/10.1007/s00264-019-04344-8

25. Guo X, Wang J, Hu D, Wu L, Gu L, Wang Y, Zhao J, Zeng L, Zhang J, Wu Y (2020) Survey of COVID-19 disease among orthopaedic surgeons in Wuhan, People's Republic of China. J Bone Joint Surg Am 102(10):847-854. https://doi.org/10.2106/jbjs.20. 00417

26. Wong KC, Leung KS (2004) Transmission and prevention of occupational infections in orthopaedic surgeons. J Bone Joint Surg Am 86:1065-1076. https://doi.org/10.2106/00004623200405000-00029

27. Jain VK, Vaishya R (2020) COVID-19 and orthopaedic surgeons: the Indian scenario. Trop Dr 50(2):108-110. https://doi.org/10. $1177 / 0049475520921616$

28. Giannoudis PV, Tzioupis C, Pape HC (2006) Fat embolism: the reaming controversy. Injury 37(4):S50-S58. https://doi.org/10. 1016/j.injury.2006.08.040

29. Hogel F, Gerlach UV, Sudkamp NP, Muller CA (2010) Pulmonary fat embolism after reamed and unreamed nailing of femoral fractures. Injury 41(12):1317-1322. https://doi.org/10.1016/j.injury. 2010.08.019

30. Mitkovic MB, Milenkovic S, Micic I, Mladenovic D, Mitkovic MM (2012) Results of the femur fractures treated with the new selfdynamisable internal fixator (SIF). Eur J Trauma Emerg Surg 38(2):191-200. https://doi.org/10.1007/s00068-011-0157-7

31. Milenkovic S, Mitkovic MM (2018) External fixation of extraarticular open tibial fractures. Acta Fac Med Naiss 35(4):330 336. https://doi.org/10.2478/afmnai-2018-0035

Publisher's note Springer Nature remains neutral with regard to jurisdictional claims in published maps and institutional affiliations. 